\title{
PRECIPITATION AND LATENT HEATING PROPERTIES OF TROPICAL CYCLONE IN THE NORTHWEST PACIFIC MEASURED BY GPM DPR AND HIMAWARI-8
}

\author{
Xiong $\mathrm{Hu}^{1}$, GuanLin $\mathrm{Li}^{2}$,Chi Zhang ${ }^{1}$, Wei Yan ${ }^{1, *}$ \\ ${ }^{1}$ College of Meteorology and Oceanography, National University of Defense Technology, 60 Shuanglong Road, Nanjing, China - \\ (huxiong18, zhangchi18)@ @udt.edu.cn, 18913979082@163.com \\ ${ }^{2}$ Unit No.93213 of PLA, Beijing, China - li201657@ outlook.com
}

Commission III, WG III/8

KEY WORDS: Tropical Cyclone, GPM, Precipitation, Dual-frequency Precipitation Radar, Himawari-8, Latent Heating

\begin{abstract}
:
Using observations from the GPM Tropical Cyclone Overpass Dataset and Himawari-8, this study statistically analyses the tropical cyclones (above Typhoon categories) in the Northwest Pacific during the tropical cyclone (TC) frequent period (from May to October) of 2014-2018. Moreover, a case (Super Typhoon "Mangkhut") was analysed in detail. This study uses a semi-manual method to identify three life cycle stages of tropical cyclones: developing stage, mature stage, and dissipating stage. The statistical results show that the distribution of precipitation and latent heat varies with positions and the tropical cyclone has the maximum precipitation $(11.62 \mathrm{~mm} / \mathrm{h})$ at the mature stage along with the maximum convection ratio $(22.97 \%)$ at the developing stage. It is most obvious that the release of latent heat in the upper cloud at developing stage and in the lower cloud at mature stage. The latent heat profile of convective precipitation presents a "bottom-heavy" structural, and the stratiform precipitation has a "top-heavy" latent heat profile. The proportion of stratiform precipitation to total precipitation $(74.31 \%)$ is the largest, but the average precipitation of the stratiform $(4.12 \mathrm{~mm} / \mathrm{h})$ is lower than the average precipitation of convective clouds $(10.55 \mathrm{~mm} / \mathrm{h})$. The average particle radius of the stratiform precipitation is $1.13 \mathrm{~mm}$, while the average precipitation particle radius of the convective cloud precipitation is $1.79 \mathrm{~mm}$. Based on these statistical results, this paper briefly analyses the characteristics of cloud precipitation microphysical mechanisms in three life cycle stages. Besides, the latent heating profile distribution found in this study are related to the vertical variation of precipitation rate, which are different in terms of the type of precipitation cloud.
\end{abstract}

\section{INTRODUCTION}

\subsection{Background}

The Northwest Pacific is one of the regions with the largest number of tropical cyclones around the world. Tropical cyclones are maintained and developed primarily by the condensation of water vapor and the release of latent heat $(\mathrm{Wu}$, 2017). A series of weather disasters caused by tropical cyclones can cause huge casualties and property losses (Stephen, 2009). The application of satellite sounding data is helpful to better understand the microphysical characteristics of tropical cyclones at developing stage, mature stage and dissipating stage and the precipitation microphysical mechanism inside precipitation clouds (Fu,2003). These works would improve the cloud model's precipitation scheme and enhance the capabilities of forecasting intensity and path of tropical cyclone (Chen, 2018).

A semi-manual method to classify tropical cyclone rainfall areas into three regions: Inner Core (IC), Inner Rain Band (IB) and Outer Rain Band (OB). Convective and precipitation properties in various regions of tropical cyclones were statistically analysed by using the 1998-2008 Tropical Rainfall Satellite (TRMM) data (Jiang, 2013). Four types of precipitation were defined in terms of the specific reflectivity factor values and the correlation shear distribution of four convective precipitation types were statistically analysed by using 14-year TRMM data (Tao, 2015). The study of the impact of cloud life cycle on the vertical structure of precipitation in eastern China based on GPM and Himawari- 8 data found that the characteristics of precipitation system in each life stage are different and the cloud water content is related to the rising motion of the air (Zhang, 2018). The precipitation efficiency index (PEI) of the tropical cyclone was proposed based on the GPM DPR data and the precipitation processes and microphysics of the tropical cyclone over the western Pacific was separated in terms of PEI values. (Huang, 2019).

Latent heating refers to the energy absorbed or released by the water particles due to phase changes (Pruppacher, 2010). It is an important part of the earth's energy and water cycle and is closely related to the precipitation process (Tao, 2006). Latent heating plays an important role during the evolution of precipitation system of tropical cyclone. Latent heating can have a huge influence on the cloud microphysical precipitation mechanism by driving the rising or sinking motion of the airflow (Yang, 2018).

\subsection{Purpose}

The purpose of this study is to learn and summarize the distribution characteristics of latent heating and precipitation microphysical properties in tropical cyclone precipitation clouds and the role of latent heating affecting particle radius and liquid water content and so on in the microphysical

\footnotetext{
* Corresponding author
} 
mechanism of cloud precipitation by taking advantages of GPM (Sun-synchronous orbit satellite) dual-frequency precipitation radar and Himawari-8 (Geosynchronous orbit satellite) for continuous observation (Pruppacher, 2010). Based on the Himawari-8 and GPM secondary standard products, tropical cyclones (above Typhoon categories) in the frequent period (from May to October) of 2014-2018 was statistically analysed. And a case (Super Typhoon "Mangkhut") was analysed in detail.

\section{DATA AND METHODOLOGY}

\subsection{GPM DPR}

The Global Precipitation Measurement (GPM) was jointly developed by NASA (National Aeronautics and Space Administration) and JAXA (Japan Aerospace Exploration Agency). It is a new generation of global satellite precipitation products after Tropical Rainfall Measuring Mission (TRMM). Its core observation platform was launched on February 28, 2014, which is equipped with Dual-frequency Precipitation Radar (DPR) and GPM Microwave Imager (GMI). DPR is the world's first spaceborne dual-frequency radar. The operating bands are $\mathrm{Ka}(35.5 \mathrm{GHz})$ and $\mathrm{Ku}(13.6 \mathrm{GHz})$, which can provide liquid water content, three-dimensional structure of precipitation distribution and latent heat distribution in precipitation clouds (Iguchi, 2002a). The KaPR has a scanning width of $125 \mathrm{~km}$ while the KuPR has a scanning width of 245 $\mathrm{km}$. Their vertical sampling interval is $125 \mathrm{~m}$ and the minimum detected echo is less than $17 \mathrm{dBZ}$. The minimum threshold for $\mathrm{KuPR}(\mathrm{KaPR})$ precipitation detection is $0.5 \mathrm{~mm} / \mathrm{h}(0.2 \mathrm{~mm} / \mathrm{h})$. There are three types of work scanning: matched mode (Ka_MS), high-sensitivity mode (Ka_HS), norm mode (Ku_NS) (Iguchi et al., 2017).

This study uses GPM secondary standard products: DPR precipitation products and Spectral Latent Heating (SLH) products. The parameters used in this study are: Corrected radar reflectivity factor, Near-surface rainfall rate, Rainfall rate profile, DSD profile, Precipitation type, Ice water path (IWP), Liquid water path (LWP), Precipitation top height $(\mathrm{PTH}), 0^{\circ} \mathrm{C}$ layer height, and Latent heating. It is noticed that in DPR standard precipitation products, the precipitation top height (PTH) is not the height relative to the surface, but the absolute height relative to the sea level (Iguchi et al., 2017).

\subsection{Himawari-8}

Himawari-8 is a new generation of geostationary meteorological satellite in Japan. It is one of the Himawariseries designed and manufactured by Japan Aerospace Exploration Agency (JAXA). It was launched on October 7, 2014 and run by the Japan Meteorological Agency (JMA) on July 7, 2015. Due to the dramatic increase in spectrum, time and spatial resolution, the advanced Himawari Imager (AHI) on the Himawari-8 has more features and better performance than the previous geostationary meteorological satellites in Japan. AHI is equipped with 16 spectral bands, from visible light $(0.47-0.86 \mu \mathrm{m})$ to thermal infrared region $(5-14 \mu \mathrm{m})$, which can be observed every 10 minutes, and a special area observation is performed every 2.5 minutes. The secondary products offered by Himawari- 8 are: Aerosol Property, Cloud Property, Photosynthetically Available Radiation, Sea Surface Temperature, Wild Fire. This study uses the Cloud Top Height $(\mathrm{CTH})$ and Cloud Top Temperature (CTT) in Cloud Property provided by Himawari-8 (Bessho, K. et al., 2016).

\subsection{Identifying Stages}

The criterion for dividing tropical cyclones into three life cycle stages is to consider the following two indicators: wind (Ying, 2014) and cloud properties. The life cycle stage is just confirmed by the whole identification of the following two methods.

\subsubsection{Best-track data set}

a. Developing stage: the period before reaching $80 \%$ of the maximum wind speed that can be maintained;

b. Mature stage: the period after reaching $80 \%$ of the maximum wind speed value that can be maintained and the period before reducing to $80 \%$ of the maximum wind speed value that can be maintained;

c. Dissipating stage: the period after reducing to $80 \%$ of the maximum wind speed that can be maintained (Han, 2013a).

\subsubsection{Cloud observation from Himawari-8}

a. Developing stage: within two hours before the observation time $(-2 \mathrm{~h} \sim 0 \mathrm{~h})$, no obvious typhoon central cloud system is formed (the cloud top temperature is lower than the nearby area and the cloud top height is higher than the nearby area), and the cloud group is more broken and incomplete; Within two hours after the observation time $(0 \sim 2 \mathrm{~h})$, some typhoon central cloud systems were formed before, and the cloud clusters gradually integrated and connected into pieces;

b. Developing stage: within two hours before the observation time $(-2 h \sim 0 h)$, a preliminary typhoon centre cloud system has been formed, and the cloud group is more complete; within two hours after the observation time $(0 \sim 2 \mathrm{~h})$, the typhoon centre cloud is basically formed. Department, cloud contiguous;

c. Dissipating stage: within two hours before the observation time $(-2 \mathrm{~h} \sim 0 \mathrm{~h})$, some typhoon centre cloud system is formed, and the cloud group is gradually integrated and connected into pieces; within two hours after observation time (0 2h), compared with before The typhoon centre cloud system gradually dissipated, and the cloud group was broken and incomplete (Zhang, 2018a).

\section{RESULT}

\subsection{Case Study}

The Super Typhoon "Mangkhut" was observed by the GPM core observation platform at 04:05-04:08 (UTC) on September 11,2018 . The tropical cyclone was moving west and at mature stage. The centre of the eye is located at $140.10^{\circ} \mathrm{E}$ and $13.75^{\circ}$ $\mathrm{N}$. The centre air pressure is $930 \mathrm{hPa}$, and the maximum wind speed can be maintained between 52-58m/s. During the followup campaign, the tropical cyclone brought heavy precipitation and damage of super-strong wind to Luzon, Hong Kong, Macau and Guangdong Province (Kel E., et al., 2018). Thus, the use and study of GPM Overpass Tropical Cyclone Data to analyse the tropical cyclone precipitation distribution and precipitation physical mechanism is conducive to monitoring and early warning of tropical cyclones (Knutson, 2010). 

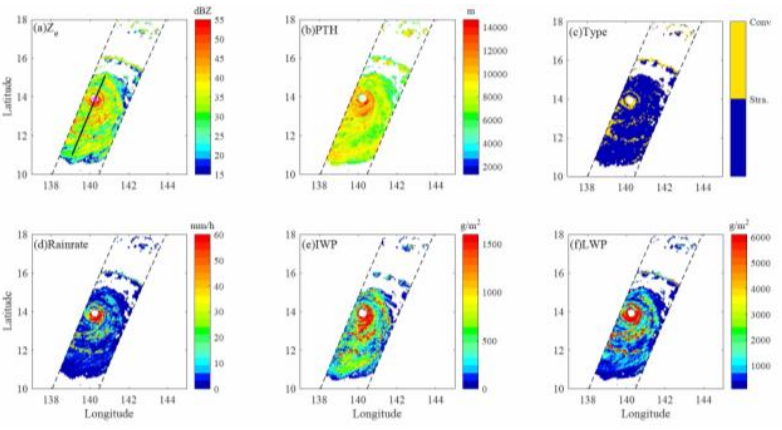

Figure 1. (a)-(f) represent the physical parameters of "Mangkhut" detected by the GPM DPR: Corrected radar reflectivity factor, Precipitation top height, Rainfall type, Near-surface rainfall rate, Ice water path (IWC), and Liquid water path (LWC).

The black dotted line in Figures 1a-f is the boundary of the GPM DPR KuPR observation range, and the “*” indicates the position of the centre of the typhoon eye.

Figures 1a, d show that the contours of the eye wall with the inner and outer spiral rain bands are clearly presented. The typhoon centre has almost no radar echoes, meaning that there is little precipitation, while the radar reflectivity factor at the eye wall and the inner and outer spiral rain band is large. Correspondingly, Figure 1d shows the spiral wall belt at the eye wall and inside and outside where near-surface rainfall rate is large and the maximum rainfall rate exceeds $60 \mathrm{~mm} / \mathrm{h}$.

Besides, Figure 1b presents that the precipitation top height in the precipitation area is basically around $4 \mathrm{~km}-12 \mathrm{~km}$, while precipitation top height near the eye wall is larger and the maximum value is more than $12 \mathrm{~km}$. This is because the eye wall is a place where convection is strong. The transition between the inner spiral rain band and the outer spiral rain band is the transition zone from convective precipitation to stratiform precipitation. Therefore, PTH decreases from the inside to the outside, and PTH is basically less than $8 \mathrm{~km}$. But PTH in the rain of the outer spiral rain band has increased to $9.5 \mathrm{~km}$ and even more. This is mainly because the outer spiral rain band is mostly the intersection of the ambient air mass and the typhoon air mass, where the temperature and humidity gradients are large, leading to the development of convective activities. Therefore, there are significant differences in the heights of different locations in the typhoon precipitation system (Pruppacher, 2010).

Moreover, Figure 1c shows that the main type of precipitation in the Super Typhoon "Mangkhut" is stratiform cloud precipitation while the main type of precipitation near the eye wall is convective cloud precipitation. The number of pixels in the stratiform cloud precipitation accounted for $79.12 \%$ of the total precipitation, and the number of pixels in the convective precipitation accounted for $18.41 \%$ of the total precipitation (Awaka, 2016). Figure 1e(f) shows that IWP (LWP) is mainly concentrated in the eye wall and the inner and outer spiral rain band, and the maximum value exceeds $1500(6000) \mathrm{g} / \mathrm{m}^{2}$.

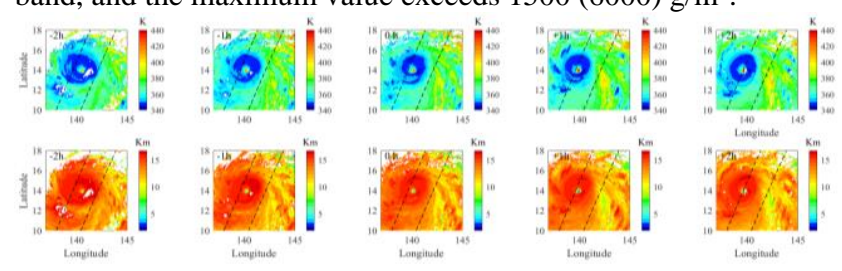

Figure 2. The detected cloud properties of "Mangkhut". The upper row (lower row) is the cloud top temperature CTT (cloud top height, CTH) observed by Himawari- 8 . The number means the period before $(-2$ hours, -1 hours $)$, meanwhile ( 0 hours) and after $(+1$ hour, +2 hours) the occurrence of GPM core observation platform.

It can be clearly shown in Figure 2 that as time goes by, the cloud systems have gradually matured and have the tendency to move westward. There are different characteristics between cloud group above typhoon centre and cloud wall of the eye wall.

On the one hand, the CTT of the eye wall cloud wall is lower than the CTT of the cloud centre near the typhoon centre and the surrounding area, which is like to "low-lying land". On the other hand, due to developing convective, the eye wall's CTH has a high height and forms a spiral cloud shaped like a "highland", enveloping a typhoon centre with a lower cloud top height (Pruppacher, 2010). These observed characteristics of tropical cyclone clouds are in good agreement with the previously analysed precipitation distribution characteristics.

In order to learn subtly the vertical structure of tropical cyclone precipitation, this study selected an orbit of GPM observation data overpass the typhoon centre, as shown by the solid black line in Figure1 a.
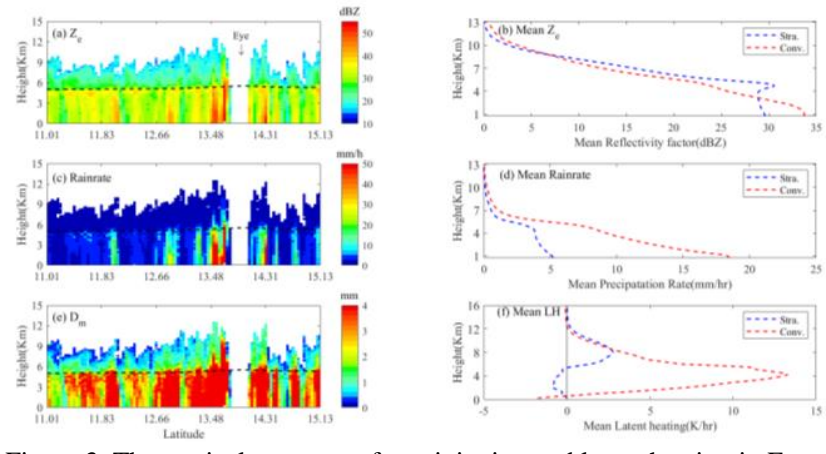

Figure 3. The vertical structure of precipitation and latent heating in Eye centre of "Mangkhut". (a), (c) and (e) present the vertical distribution of latitudinal-height for Radar reflectivity factor, Near-surface rainfall rate and Particle radius. (b), (d) and (f) show the average-height vertical distribution of Radar reflectivity factor, Rainfall rate and Latent heating in terms of stratiform precipitation and convective precipitation.

The position of the eye wall has been marked in the Figure 3 a. The black dashed line indicates the height of the zero-degree layer, and the average height of the zero-degree layer is 5.14 $\mathrm{km}$.

Figure $3 \mathrm{a}$ shows that the larger value of the radar reflectivity factor is mainly concentrated below the zero-degree layer, and rarely exceeds $30 \mathrm{dBZ}$ above the zero-degree layer. Since the precipitation of the stratus cloud accounts for a large proportion of the total precipitation, the reflectivity factor at 100-400 m below the $0{ }^{\circ} \mathrm{C}$ height line is obviously enhanced, forming a relatively bright band. The Reflectivity factor (Near-surface precipitation rate) in the southern part of the typhoon eye exceeds $50 \mathrm{dBZ}(45 \mathrm{~mm} / \mathrm{h})$ and the echo intensity is also significantly higher than the north side of the typhoon eye, which reflects the typical asymmetrical structure of the typhoon (Cecil, 2002a).

The larger rainfall rate (particle diameter) is mainly concentrated below the zero-degree layer, and rarely exceeds 12 $\mathrm{mm} / \mathrm{h}(2 \mathrm{~mm})$ above the zero-degree layer. As the height decreases, the precipitation rate and particle radius tend to increase, indicating that the raindrops continuously touch and 
grow during the falling process, resulting in the diameter of the raindrop particles becoming larger and the rainfall rate increasing. The latent heating profile of convective precipitation presents a distinct bottom-heavy structural feature, while the stratiform precipitation has a top-heavy latent heat profile (Houze, 1989).

\subsection{Statistic Study}

In this statistic study, 36 tropical cyclones (17SuperTyphoon, 19Typhoon) in the tropical cyclone frequent period (MayOctober) of 2014-2018 were selected for detailed statistical analysis.

The following points can be drawn from the Table 1: a. In any life cycle stage, the ratio of stratiform precipitation to total precipitation is the highest, but the average surface precipitation rate of stratiform precipitation is lower than the average of convective precipitation;

b. The stratiform precipitation $(4.45 \mathrm{~mm} / \mathrm{h})$, convective precipitation $(11.62 \mathrm{~mm} / \mathrm{h})$ and average of near-surface precipitation rate $(5.82 \mathrm{~mm} / \mathrm{h})$ at the mature stage are more than the other two stages;

c. The airflow in the cloud rises and the convection develops vigorously at developing stage, giving rise to the largest convection ratio (22.97\%), while the airflow rise is hindered and the convection is weakened at dissipating stage, resulting in a minimum convection ratio $(17.59 \%)$.

\begin{tabular}{cccc}
\hline & Developing & Mature & Dissipating \\
\hline $\begin{array}{c}\text { Granules } \\
\text { (Orbits) } \\
\text { Mean Rain }\end{array}$ & $23(1127)$ & $25(1225)$ & $13(637)$ \\
Rate(mm/h) & 4.98 & 5.82 & 4.88 \\
$\begin{array}{c}\text { Stratiform } \\
\text { Precipitation }\end{array}$ & 71.49 & 72.22 & 79.21 \\
$\begin{array}{c}\text { Proportion (\%) } \\
\text { Mean rain rate } \\
\text { of stratiform } \\
\text { (mm/h) }\end{array}$ & 3.76 & 4.45 & 4.16 \\
$\begin{array}{c}\text { Convective } \\
\text { Precipitation }\end{array}$ & 22.97 & 22.41 & 17.59 \\
$\begin{array}{c}\text { Proportion (\%) } \\
\text { Mean rain rate } \\
\text { of convective } \\
\text { (mm/h) }\end{array}$ & 9.78 & 11.62 & 10.26 \\
\hline
\end{tabular}

Table 1. The statistic result for precipitation of selected TCs
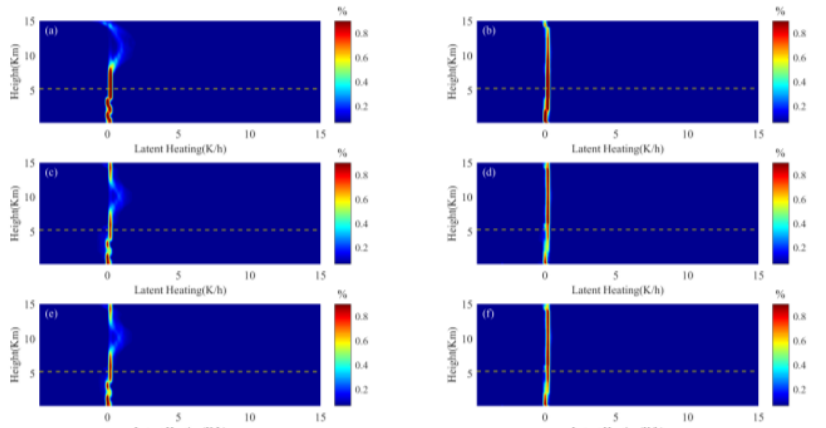

Later Heating(x)

Figure 4 . The Contoured frequency by altitude diagrams for latent
heating average of stratiform and convective precipitation at each stage The left (right) column represents the latent heating average profiles of stratiform precipitation (convective cloud precipitation), while rows 1 to 3 respectively represent the stages of developing, mature and dissipating.

The yellow lines in Figure 4 represent the $0{ }^{\circ} \mathrm{C}$ layer height of stratiform precipitation and convective precipitation in three life cycle stages. The average value ranges from 5.19 to $5.27 \mathrm{~km}$.

It can be shown clearly in Figure 4 that the release of latent heating is mainly concentrated above and below the $0{ }^{\circ} \mathrm{C}$ layer. The latent heating profile of convective precipitation exhibits obvious bottom-heavy structural characteristics, and the release of latent heating is mainly below the $0^{\circ} \mathrm{C}$ layer. The stratiform precipitation has a top-heavy latent heating profile, and the release of latent heating is mainly above the $0^{\circ} \mathrm{C}$ layer. The precipitation is the strongest at mature stage. However, the latent heating is released mostly in the upper layer of cloud at developing stage and in the low layer of the cloud at the mature stage (Houze, 1989).
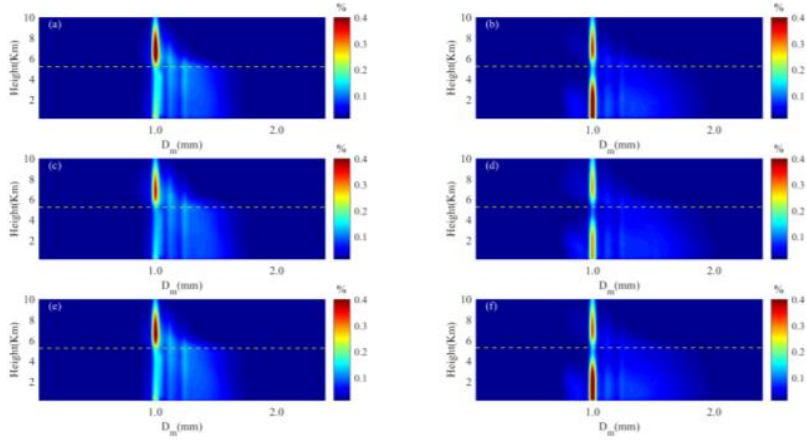

Figure 5. The Contoured frequency by altitude diagrams for droplet radius average of stratiform and convective precipitation at each stage. The stages of developing, mature, and dissipating stage was indicated respectively from the rows 1 to 3 . The left (right) column indicates the style of stratiform cloud precipitation (convective cloud precipitation).

The yellow line in Figure 5 indicates the $0^{\circ} \mathrm{C}$ layer of stratiform precipitation and convective precipitation in three life cycle stages. The average of height ranges from 5.19 to $5.27 \mathrm{~km}$.

Figures 5a, c and e present that the particle radius average of the stratus precipitation is concentrated and the maximum value is less than $2 \mathrm{~mm}$, and the small particles are mainly concentrated above the $0^{\circ} \mathrm{C}$ layer which mainly are ice crystal grains and supercooled water droplets. Figures $5 b$, $d$ and $f$ show the convective cloud average precipitation particle radius spans a large value and the maximum value can exceed $2 \mathrm{~mm}$. Small particles are mainly distributed below the $0{ }^{\circ} \mathrm{C}$ layer, and some small particles are concentrated above the $0^{\circ} \mathrm{C}$ layer.
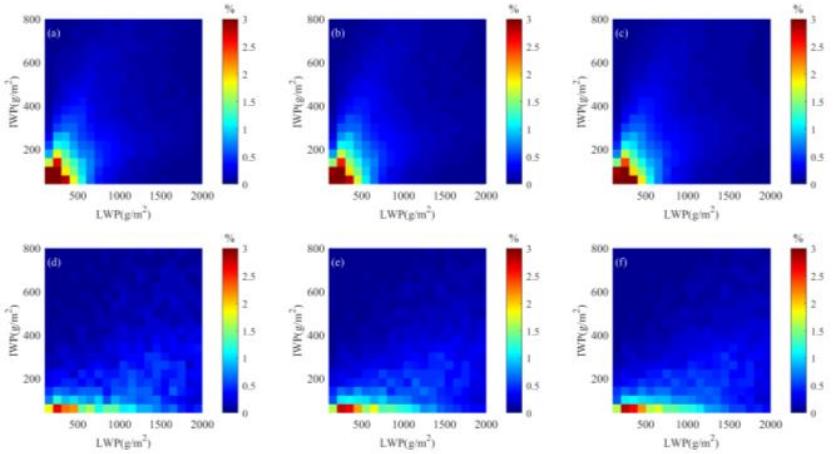

Figure 6. The frequency pattern in two-dimensional space of Ice water path and Liquid water path for stratiform and convective precipitation at each stage. The upper row (a)-(c) (lower row (d)-(e)) represent the style of stratiform cloud precipitation (convective cloud precipitation), while columns 1 to 3 represent developing, mature, and dissipating stage. 
The average particle radius of the stratus precipitation is 1.13 $\mathrm{mm}$, while the average precipitation particle radius of the convective cloud precipitation is $1.79 \mathrm{~mm}$. The cloud water content in the stratiform precipitation cloud is dominated by IWP; The cloud water content in the convective cloud precipitation cloud is dominated by LWP (Wen, 2016). It can be seen from Figure 5 and Figure 6 that the cloud liquid water form in the stratiform precipitation cloud is dominated by ice crystal particles, supercooled water droplets and small cloud droplets, while the cloud liquid water form in the convective cloud precipitation cloud is dominated by small cloud droplets and raindrops (Houze,1997). This is mainly because the convective development of the stratiform precipitation cloud is not strong and the thickness of the cloud is small, which means there is not enough decline process to allow the particles to fully touch and grow. The convection of the convective cloud precipitation cloud is strong and the thickness of the cloud is large, so the raindrops have enough range to bump and grow in the formation process. (Pruppacher, 2010).

According to the above statistical results, the characteristics of the cloud precipitation microphysical mechanism of tropical cyclone at each life cycle stages can be analysed as follows:

a. Developing stage: The humid air of the sea surface is converged into the cloud, following the organized updraft in the cloud. The water vapor condensing releases a large amount of latent heat, causing the temperature inside the cloud higher than the ambient temperature and promoting the cloud development. b. Mature stage: The cloud is still dominated by updrafts, but due to the formation of more precipitation at this stage, the formation of organized downdrafts begins to form under the drag of precipitation particles. The temperature of the downdraft region is lower than the ambient temperature, so that the divergent airflow begins to appear under the cloud, and the maintenance and development of convection is inhibited.

c. Dissipating stage: The cloud is mainly organized with a downdraft, completely blocking the updraft. At the same time, the sinking cold air can lift the humid air adjacent to the surrounding area, thus triggering new monomer generation (Houze, 2010).

\section{DISCUSSION AND CONCLUSION}

\subsection{Discussion}

This paper is a preliminary study of the relationship between precipitation and latent heat of tropical cyclones and cloud precipitation physics. There are still many places to be discussed and improved, as listed below:

a. The core of the GPM SLH algorithm is to generate the latent heat data generated by the lookup table based on the measured physical quantity of precipitation measured by DPR. The algorithm itself still has defects and needs to be further improved.

b. The extensiveness of the statistical samples used in this study is still insufficient and does not cover tropical cyclones of all intensity levels. The next study may consider statistical samples that encompass tropical cyclones of all intensity levels.

c. Due to the asymmetry of the tropical cyclone structure and the difference in precipitation distribution in different regions, it can be considered to divide into three regions according to the statistical distance feature value or the summarized regional characteristics: Inner Core, Inner Rain Band, Outer Rain Band. Sub-regional statistical analysis and research.

d. The statistical results of the distribution of latent heat profiles found in this study are related to the statistical vertical variation of precipitation rate, and this correlation has different characteristics depending on the type of precipitation cloud. Therefore, the relationship between the potential heat profile distribution and the precipitation rate gradient needs to be further explored (Stephen, 2018).

\subsection{Conclusion}

This study combines the advantages of GPM (Sun-synchronous orbit satellite) dual-frequency radar to detect cloud rain and the advantage of Himawari-8 (Geosynchronous orbit satellite) for continuous high-temporal resolution of the region. The main points are summarized as follows:

a. The asymmetrical structure around the eye of the tropical cyclone centre is different, and the features of precipitation and latent heat distribution are different.

b. No matter which stage of the life cycle, stratiform precipitation accounts for the largest proportion of total precipitation, but the average precipitation of stratus clouds is lower than the average precipitation of convective clouds;

c. During the mature stage, the precipitation is the strongest and the convection ratio is the largest. However, the latent heating is released mostly in the upper layer of cloud at developing stage and in the low layer of the cloud at the mature stage.

d. The latent heat profile of convective precipitation presents obvious bottom-heavy structural while the stratiform precipitation has a top-heavy latent heat profile.

Besides, the statistical results of the potential heat profile distribution found in this study are related to the statistical vertical variation of precipitation rate, and this correlation has different characteristics depending on the type of precipitation cloud. Therefore, the relationship between the potential heat profile distribution and the precipitation rate gradient needs to be further explored.

\section{ACKNOWLEDGEMENTS}

The GPM Tropical Cyclone Overpass Dataset is provided by Japan Aerospace Exploration Agency Earth Observation Research Centre (JAXA/EORC).

The tropical cyclone Best-track Dataset is downloaded from tcdata.typhoon.org.cn and Unisys Weather.

\section{REFERENCES}

Awaka, J., Iguchi, T., 2016. Rain type classification algorithm module for GPM dual- frequency precipitation radar. Journal of Atmospheric and Oceanic Technology, 33(9), 1887-1898.

Bessho, K., et al., 2016. An introduction to Himawari-8/9Japan's new-generation geostationary meteorological satellites. J. Meteor. Soc. Japan, 94, 151-183.

Cecil, D. J., Zipser, E. J., Nesbitt, S. W., 2002. Reflectivity, ice scattering, and lightning characteristics of hurricane eyewalls 
and rain-bands. Part I: Quantitative description. Monthly Weather Review, 130(4), 769-784.

Chen, F., Sheng, S., Bao, Z., Wen, H., Hua, L., Paul, N. J., Fu, Y., 2018. Precipitation clouds delineation scheme in tropical cyclones and its validation using precipitation and cloud parameter datasets from TRMM. Journal of Applied Meteorology and Climatology, 57(4), 821- 836.

Fu, Y., Liu, G., 2003. Precipitation characteristics in midlatitude East Asia as observed by TRMM PR and TMI. Journal of the Meteorological Society of Japan, 81(6), 1353-1369. https://doi.org/10.2151/jmsj.81.1353

Han Ding, Yan Wei, Ye Jing, et al. 2013. Analyzing cloud, precipitation, and thermal structure characteristics of typhoons in eastern Pacific based on CloudSat satellite data. Chinese Journal of Atmospheric Sciences (in Chinese), 37 (3): 691-704.

Houze, R., 1989. Observed structure of mesoscale convective systems and implications for large-scale heating. Quarterly Journal of the Royal Meteorological Society, 115, 425-461.

Houze, R. A. Jr., 1997. Stratiform precipitation in regions of convection: A meteorological paradox? Bulletin of the American Meteorological Society, 78, 2179-2196.

Houze, R. A., 2010. Clouds in tropical cyclones. Monthly Weather Review, 138(2), 293-344.

Huang, H., Chen, F., 2019. Precipitation microphysics of tropical cyclones over the western North Pacific based on GPM DPR observations: A preliminary analysis. Journal of Geophysical Research: Atmospheres, 124, 3124-3142.

Iguchi, T., Oki, R., Smith, E., Furuhama, Y., 2002. Global precipitation measurement program and the development of dual- frequency precipitation radar. Journal - Communications Research Laboratory, 49, 37-46.

Iguchi, T., Seto, S., Meneghini, R., Yoshida, N., Awaka, J., \& Kubota, T., 2017. GPM/DPR level- 2 algorithm theoretical basis document. NASA Goddard Space Flight Center, Greenbelt, MD, USA, Tech. Rep.

Jiang, H., Ramirez, E. M., Cecil, D. J., 2013. Convective and rainfall properties of tropical cyclone inner cores and rainbands from 11 years of TRMM data. Monthly Weather Review, 141(2), 431-450.

Kel E., et al., 2018, GPM Captures Super Typhoon Mangkhut Approaching the Philippines. https://svs.gsfc.nasa.gov/4682

Knutson, T. R., McBride, J. L., Chan, J., Emanuel, K., Holland, G., Landsea, C., 2010. Tropical cyclones and climate change. Nature Geoscience, 3(3), 157-163.

Pruppacher, H. R., Klett, J. D., 2010. Microphysics of Clouds and Precipitation ( $2^{\text {nd }}$ ed.). Dordrecht: Springer.

Stephen, L., W, Tao., 2018. The Next-Generation Goddard Convective-Stratiform Heating Algorithm: New Tropical and Warm-Season Retrievals for GPM. Journal of Climate, 31(6), 5997-6026.
Stephen L., Durden, Simone T., 2009. CloudSat and A-Train Observations of Tropical Cyclones. The Open Atmospheric Science Journal, 2009, 3, 80-92

Tao, C., Jiang, H., 2015. Distributions of Shallow to Very Deep Precipitation-Convection in Rapidly Intensifying Tropical Cyclones. Journal of Climate, 28(4), 8791-8824.

Wen, L., Zhao, K., Zhang, G., Xue, M., Zhou, B., Liu, S., \& Chen, X., 2016. Statistical characteristics of raindrop size distributions observed in East China during the Asian summer monsoon season using 2- D video disdrometer and Micro Rain Radar data. Journal of Geophysical Research: Atmospheres, 121, 2265-2282. https://doi.org/10.1002/2015JD024160

Wu S., Brain J.,2017. Signatures of tropical cyclone intensification in satellite measurements of ice and liquid water content. Monthly Weather Review, 145(8), 4081-4091.

Ying, M., W. Zhang, H. Yu, X. Lu, J. Feng, Y. Fan, Y. Zhu, and D. Chen, 2014: An overview of the China Meteorological Administration tropical cyclone database. J. Atmos. Oceanic Technol., 31, 287-301.

Zhang, A., Fu, Y., 2018. Life cycle effects on the vertical structure of precipitation in East China measured by Himawari8 and GPM DPR. Monthly Weather Review, 146(7),2183-2199. 